E3S Web of Conferences 1, 09007 (2013)

DOI: $10.1051 / \mathrm{e} 3$ sconf/20130109007

(c) Owned by the authors, published by EDP Sciences, 2013

\title{
Determination of the Organophosphorus Pesticide Diclorvos by Enzymatic Flow- Injection Analysis with Conductimetric Detection
}

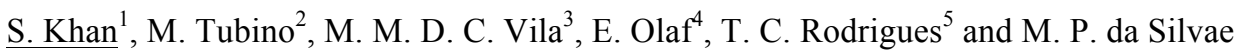 \\ ${ }^{1}$ Institute of Chemistry, University of Campinas, 13083-970 Campinas, São Paulo, Brazil \\ ${ }^{2}$ Pharmacy Course, Sorocaba University, Sorocaba, SP, Brazil, *tubino@iqm.unicamp.br \\ ${ }^{3}$ Hochschule für Angewandte Wissenschaften, HAW, Hamburg, Germany \\ ${ }^{4}$ Universidade do Estado de Minas Gerais, UEMG, Brazil. \\ ${ }^{5}$ Instituto Federal da Bahia, Campus Ilhéus, Ilhéus, Brazil
}

\begin{abstract}
Brazil is one of the world largest consumers of pesticides. When used properly pesticides help increase production. But when misused they can be extremely detrimental to the environment and to the population, which has led civil society to demand tighter control from environmental agencies and increased the demand for analytical data. In this work, we developed a scanning method for the determination of organophosphorus pesticides using a FIA procedure associated with an enzymatic biosensor based on acetyl cholinesterase. Although immunosensor systems have been proposed as powerful pesticide monitoring tools. The method is based on the generation of acetic acid by the reaction of acetylcholine with the enzyme cholinesterase. Which was chemically immobilized on "CPG" the acetic acid formed permeate through a poly(tetrauoroethylene) (PTFE) membrane into a de-ionized water stream. The developed method is extremely simple, sensitive and low cost and selective for inhibitors of this enzyme. For the pesticide paroxon the detection limit was about $10^{-18} \mathrm{~mol} \mathrm{~L}^{-1}$, the correlation coefficient was 0.9966 and the standard deviation of $0.0403(\mathrm{n}=6)$.
\end{abstract}

Key words: Organophosphorus pesticides; Inhibition; acetyl cholinesterase.

\section{Introduction}

Brazil is one of the world's largest consumers of pesticides. The insecticides and organophosphorus pesticides (OPs) are widely used in agriculture worldwide [1]. The biosensors working on the basis of enzyme inhibition have been widely used to perform the detection of organophosphorus compounds [2]. The proposed method is based on the formation of acetic acid by reacting acetylcholine with acetyl cholinesterase enzyme and the resulting acetic acid permeates through a diffusion membrane, under a stream of deionized water, being detected using conductometry [3].

\section{Methods and Materials}

A schematic flow diagram for the conductimetric determination of acetylcholine is shown in Fig. 1. The injected sample of acetylcholine (S) is combined with the carrier stream (A2), a $0.1 \mathrm{~mol} \mathrm{~L}^{-1}$ phosphate buffer at $\mathrm{pH}$ 7.5 pumped at a flow rate of $1.0 \mathrm{ml} \mathrm{min}{ }^{-1}$, and is passed through the enzyme reactor (ER) situated in a polyethylene tube $3.5 \mathrm{~cm}$ long and $3 \mathrm{~mm}$ in diameter Fig. 1. After passing through the enzyme reactor the solution joins with the $0.5 \mathrm{~mol} \mathrm{~L}^{-1}$ of sulfuric acid stream $\left(\mathrm{A}_{3}\right)$ and passes through the diffusion cell (M). Then, the acetic acid that diffuses through the PTFE membrane is carried out by the de-ionized water stream $(\mathrm{Al})$ to the conductimetric cell (FC).

\section{Result and Discussion}

The recent method for determination of pesticides is indirect. The method is based on the enzymatic reaction between the substrate and the enzyme acetilcolinestarase immobilized on glass beads, which generates acetic acid. The resulting acetic acid upon further contact with sulfuric acid solution has increased its diffusion through the PTFE membrane. It is necessary that the product of the enzymatic reaction is acidified with $\mathrm{H}_{2} \mathrm{SO}_{4}(0.5 \mathrm{~mol}$ $\mathrm{L}^{-1}$ ) to lower the $\mathrm{pH}$, thus allowing all the acetic acid is in unionized form (molecular protonated) and not in the form of acetate. 


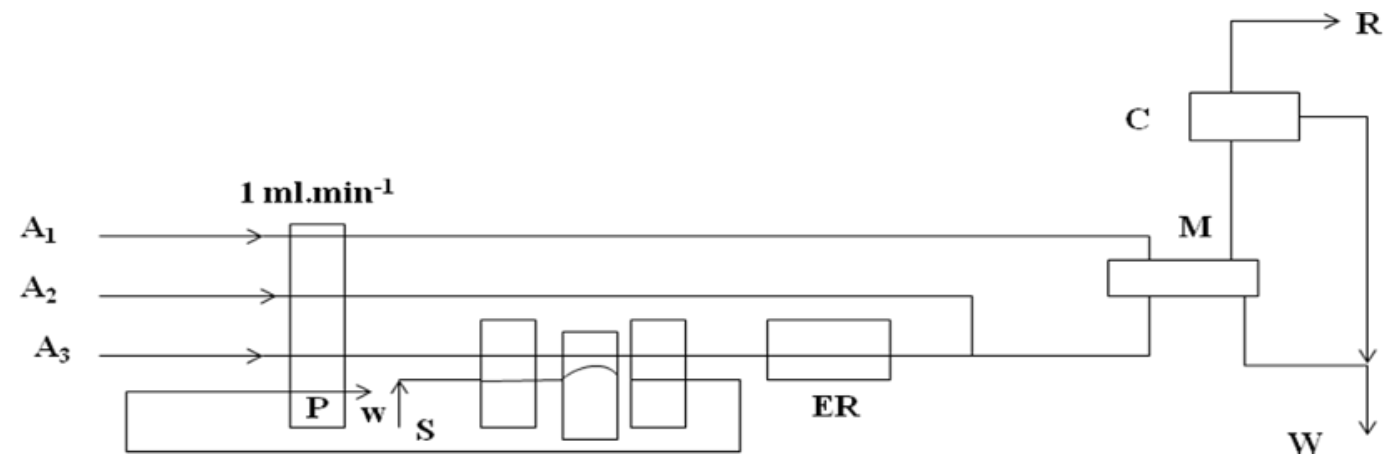

Fig. 1. Schematic of the flow injection system. Al, flow of deionized water, A2, $0.1 \mathrm{~mol} \mathrm{~L}^{-1}$, the flow of phosphate buffer, A3, sulfuric acid concentration of $0.5 \mathrm{~mol} \mathrm{L-1,} \mathrm{B,} \mathrm{water} \mathrm{bath,} \mathrm{P,} \mathrm{peristaltic} \mathrm{pump;} \mathrm{S,} \mathrm{sample} \mathrm{volume,} \mathrm{ER,} \mathrm{enzyme}$ reactor, $\mathrm{M}$, diffusion cell, $\mathrm{C}$, conductivity, $\mathrm{R}$, recorder.

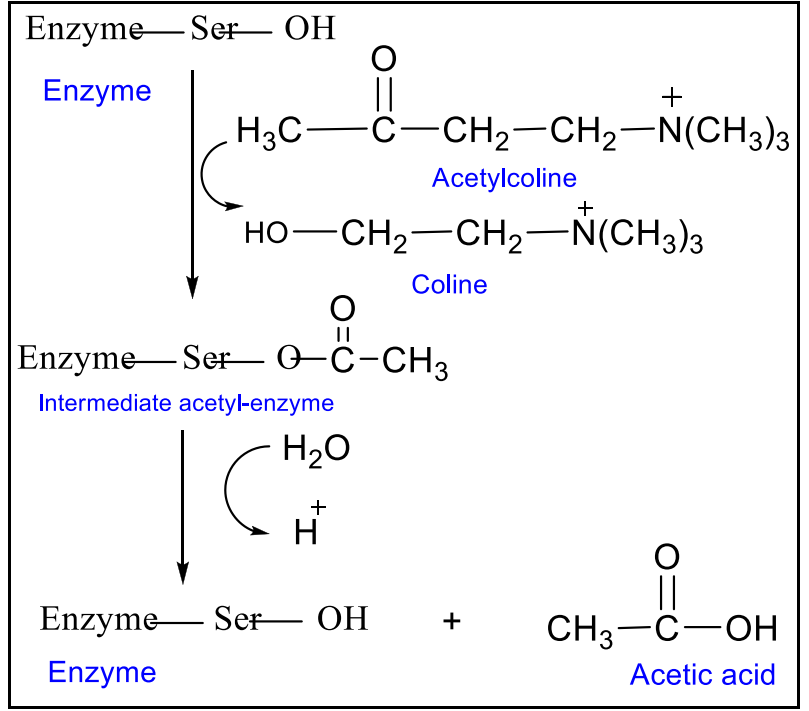

Fig. 2. Catalytic reaction of acetylcholine with acetylcholinesterase (Rodrigues, 1998)

The curve of $\%$ inhibition versus logarithmic concentration of oxidized paraoxon is described by the equation: $\mathrm{S}=41.16619+2.344 \log \mathrm{M}$, where $\mathrm{S}$ represents the percentage of inhibition and $M$ concentration.

The compound formed after the addition of bromine water oxidation takes place and confirmed by GCMS and Mass spectroscopy as show in the following figure.

The correlation coefficient for this curve is 0.9966. The average standard deviation is $0.0403 \%(\mathrm{n}=$ 13) for the concentration range $1.0 \times 10^{-5}$ to $1.0 \times 10^{-17}$ mol L $\mathrm{L}^{-1}$ and the $\%$ inhibition was in the range of $15.2 \%$ to $3.2 \%$. For pesticide determinition of red capsicum sample. Solutions of Red capsicum were added to different pesticides solution in the range of $1.0 \times 10^{-11}$ to $1.0 \times 10^{-14} \mathrm{~mol} \mathrm{~L}^{-1}$ and added bromine water for its oxidattion. The inhibition percentages obtained were in the range of $7.2-14.3 \%$.

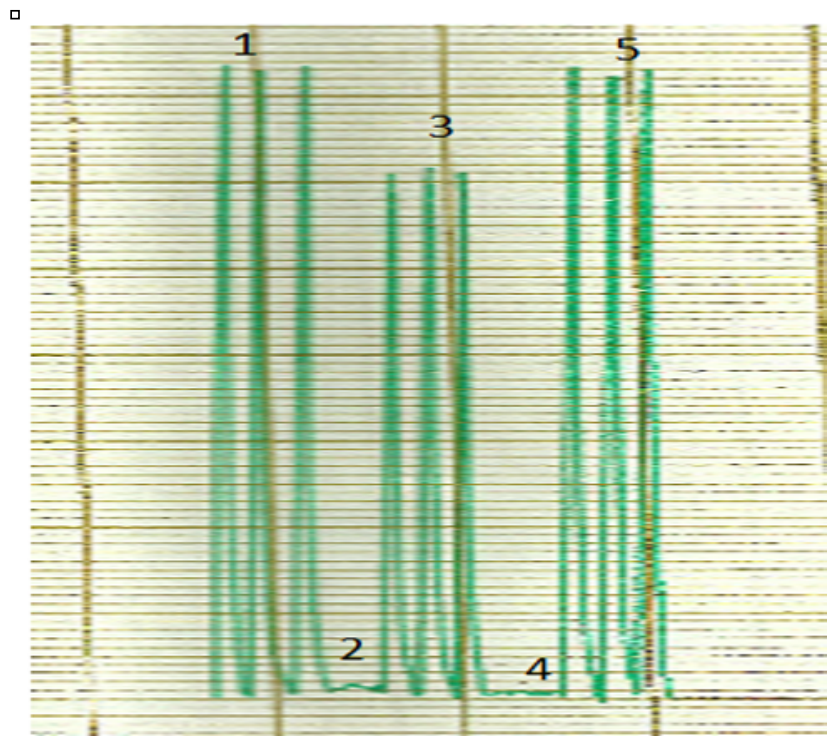

Fig. 3. Representing the determination of a pesticide acetylcholinesterase inhibitor: (1) signals in triplicate of substrate concentration of $5.0 \times 103 \mathrm{~mol}-\mathrm{L}-1$ (2) signal of an organophosphate solution, (3) signals in triplicate of the substrate after the enzyme inhibition, (4) signal regenerator enzymatic TMB-4, (5) signals in triplicate after regeneration of the enzyme substrate.

\section{Conclusion}

In the present study the proposed analyitical protocol for the determination of paraoxon is satisfactory for the quantative analysis of paraoxon in the studied concentration range. The method were cast effective, precise and need very small volumes of the reagents. Morover the enzyme reactor can be used for more than 4 months with good and normal activity.

\section{Acknowledgments}

The authors thank the financial supports providing from TWAS and CNPq. 


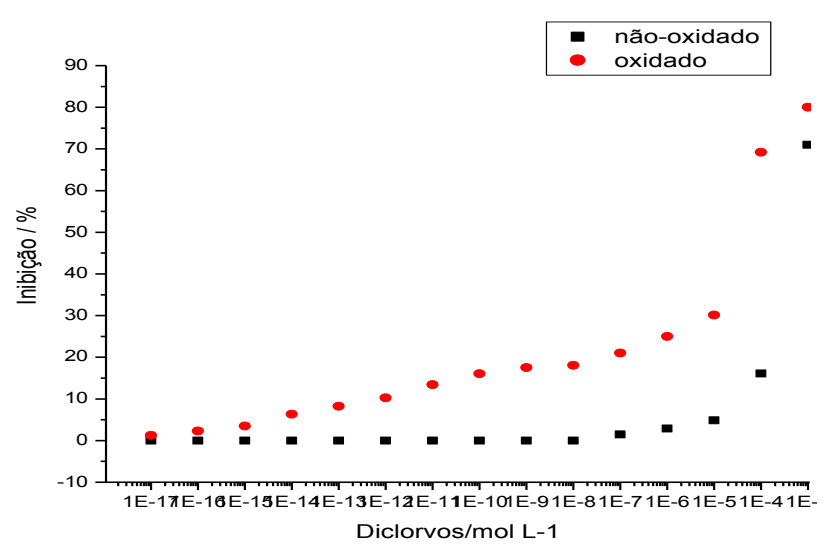

Fig. 4. Relationship between the percentage of inhibition of acetylcholinesterase (.) before oxidation (.) after the oxidation with bromine water. Concentration of acetylcholinesterase $=5.0 \times 10^{-3} \mathrm{~mol} \mathrm{~L}^{-1}$; phosphate buffer $\mathrm{pH}=7.5$, injection volume $=150 \mu \mathrm{L}$, sulfuric acid concentration $=0.5 \mathrm{~mol} \mathrm{~L}-1$, flow rate $=1.0 \mathrm{~mL} \mathrm{~min}-1$.

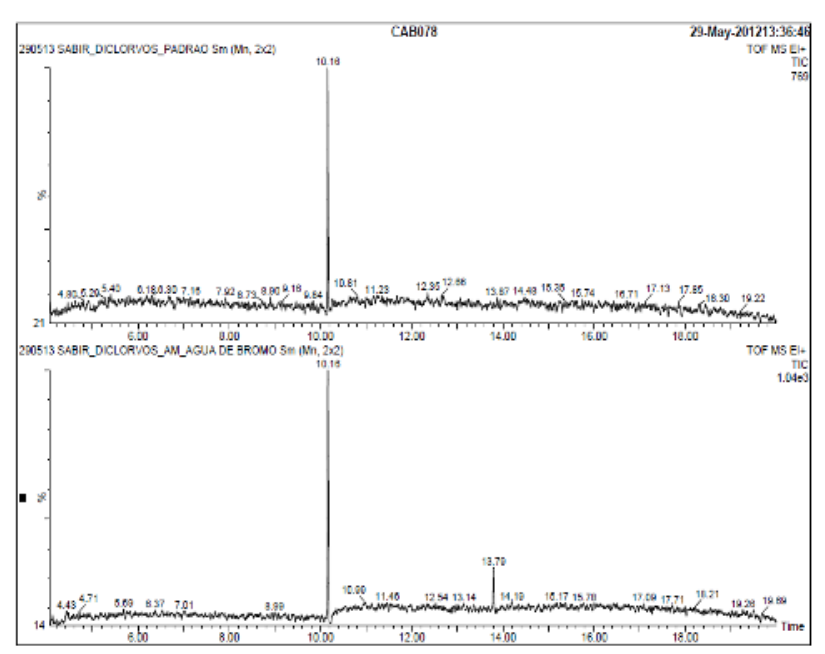

Fig. 5. GCMS Espectras for standards and sample

\section{References}

X. Cheng, Z. Zhang, S. Tian, Spectrochimica Acta Part A. 67 (2007) 1270-1275.

R.P. Deo, J. Wang, I. Block, A. Mulchandani, A. Kanchan, J.M. Trojanowiczd, F. Scholzb, W.

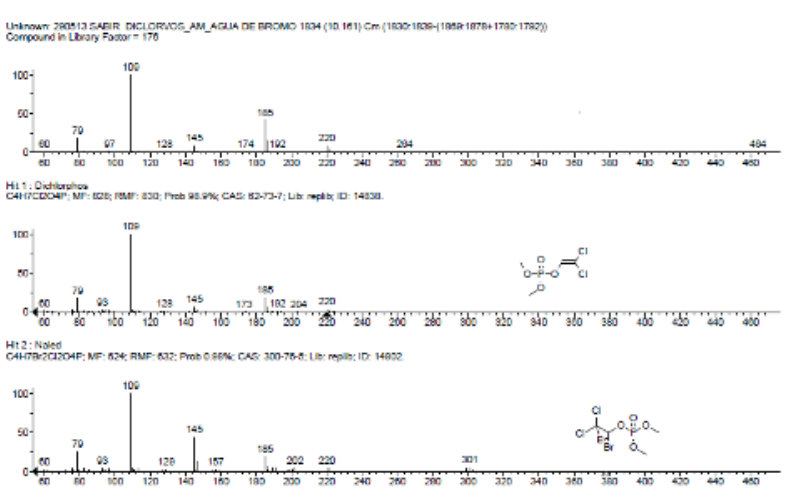

Fig. 6. Mass Spectra of the standard

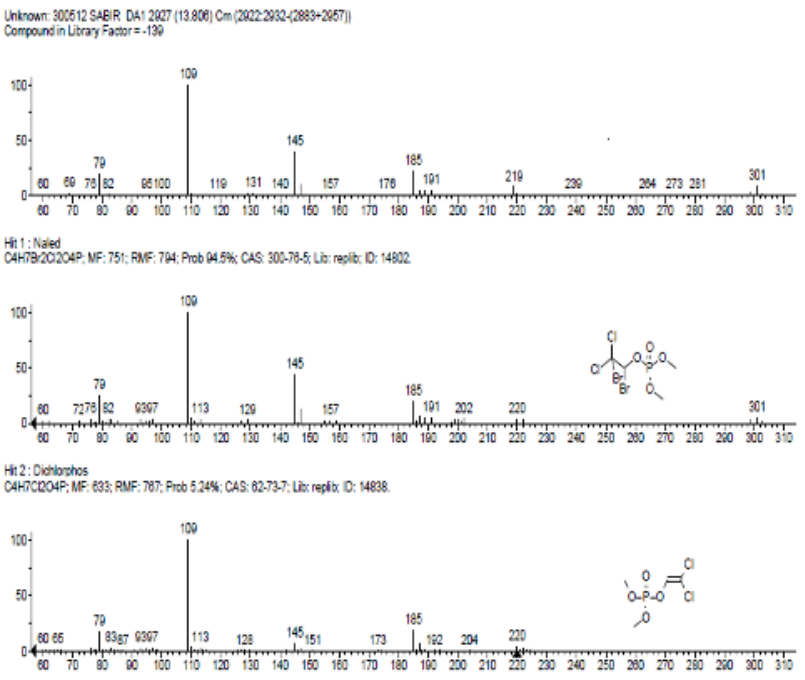

Fig. 7. Mass spectra of the Sample

Chenc, Y. Line. Analytica Chimica Acta. 530 (2005) 185-189,

E. S. G. Oswaldo, C. R.Tereza, M. Tubino, N. Oliveira, L. M.Aleixo,. Analytical Proceedings Including Analytical Communications. 32, (1995) 333-335. 